\title{
Morphological and Histological Study of Human Foetal Thymus Gland
}

\author{
Vijaya Ramanathan ${ }^{1}$, Sreelekha Dorairaj ${ }^{2}$
}

${ }^{1}$ Associate Professor, ${ }^{2}$ Assistant Professor,

Department of Anatomy, Meenakshi Medical College and Research Institute, Enathur, Kanchipuram.

\section{ABSTRACT}

Background: There is typical involution of thymus gland due to steroid mediated immune response in many intrauterine infections. A simple study of morphology and histology of foetal thymus gland at different gestational age can help us identify these diseases early.

Materials and Methodology: Thirteen still born foetuses ranging from 12 to 36 weeks were examined. The morphology and histology using (i) Haematoxylin and eosin (ii) Tannic acid, phosphomolybdic acid and amido black (TPA) (iii) Masson's trichrome stains were studied.

Result: The measurement of the gland was compared with its CRL. The weight of the gland and foetus were compared to the gestational age. The capsule, septae, cortex, medulla, blood vessel, lymphocytes, reticular epithelial cells, adipose cells and Hassall's corpuscle were demonstrated.

Conclusion: The involution of thymus gland, reflected in its morphology and histology can serve as a baseline to identify pathological conditions.

Keywords: Foetal thymus, morphology, reticular epithelial cells, adipose cells, Hassall's corpuscle, Haematoxylin eosin, Tannic acid phosphomolybdic acid amido black (TPA), Masson's trichrome.

\section{INTRODUCTION:}

$\mathrm{T}$ he thymus, is the source of immunologically competent CD4 and CD8 lymphocytes. ${ }^{1,2}$ Age related involution, of thymus gland beyond puberty, is a typical feature evolutionarily maintained in vertebrates. ${ }^{3}$ This occurs due to increased circulating level of sex hormones. ${ }^{2}$ Intrauterine infection or stress, leads to steroid mediated immune response and this involutes the foetal thymus gland. Intraamniotic infection during pregnancy is not clinically apparent and requires invasive tests of amniotic fluid, but the simple measurement of foetalthymic size to the gestational age can help in assessing the pathology. ${ }^{4}$ Also in respiratory distress syndrome, the gland involutes in size in response to raised circulating glucocorticoid and thus can serve as an important indicator of the disease. ${ }^{5}$ The size of thymus depends on genetics and early life nutrition, particularly the zinc level and can become an indirect predictor of nutritional status of the developing foetus. ${ }^{2}$ The measurement of foetal thymus allows early diagnosis of chorioamnionitis and this is useful in diagnosing premature rupture of membrane. ${ }^{6}$ The size of thymus gland in adults and in infants have been examined using computed tomography, ${ }^{7,8}$ and ultrasonography images, ${ }^{10}$ but the present study focuses on direct visualization of the gland by foetal autopsy. Therefore, the simple morphological details and microscopic anatomy of 
foetal thymus which predicts its maturity can serve as an important adjunct in diagnosing many diseases.

\section{MATERIALSAND METHODS :}

Thirteen still born foetal specimens ranging from 12 to 36 weeks were procured from the department of Obstetrics and Gynecology. Institutional ethical committee clearance was obtained. Seven female and six male fetuses which were free from detectable gross anomalies. The foetuses were examined for their respective crown rump lengths, gestational ages and body weights were used for the study. They were fixed in $10 \%$ formalin for 10 days and then subjected to dissection. The extent of the gland, shape and the number of lobes were noted, photographs taken and the gland was removed. The base width and maximum height of thymus gland were measured using a measuring scale. The weight of the thymus gland was assessed using digital weighing balance. The histological study included staining the thymus section using (i).Hematoxylin and eosin, (ii) Tannic acid, phosphomolybdic acid and amido black (TPA) and (iii) Masson's trichrome stains. The connective tissue elements such as capsule, septae, the parenchyma including cortex, medulla, blood vessels, the cytology of lymphocytes, reticular epithelial cells, adipose cells and Hassall's corpuscle were demonstrated.

\section{OBSERVATIONAND RESULTS :}

\section{MORPHOLOGY}

\section{Extent :}

The thymus tapered into the neck above cricoid cartilage in 10 specimens, extended up to cricoid cartilage in 1 specimen and to thyroid gland level in 2 foetal specimens. In all the specimens the gland extended below to overlap the pericardium. (Figure1).

\section{Number of Lobes:}

There were two distinct smooth lobes which were asymmetrical in 11 specimens. They were enclosed in a capsule and the lobes were interconnected by fibrous tissue. Two specimens showed multiple surface lobulations. (Figure 2)

\section{Shape:}

The thymus gland was pyramidal in 5 foetal specimens (Figure 3), oval in 6 specimens, and had a moulded appearance in 2 specimens, being moulded to the adjacent structures.

\section{Measurement:}

Table 1 gives the measurement of the gland in ascending order with respect to the CRL of the foetus.

\section{Weight:}

Table 2 compares the estimated gestational age, weight of foetus and thymus gland.

Table 1. Measurement of thymus in comparison with crl of foetus

\begin{tabular}{|c|c|c|}
\hline Sl. No. & CRL (cm) & $\begin{array}{c}\text { Measurement of thymus } \\
\text { Base X height (cm) }\end{array}$ \\
\hline 1. & 10 & $0.6 \times 0.5$ \\
\hline 2. & 11.5 & $0.7 \times 0.4$ \\
\hline 3. & 12 & $1.3 \times 0.5$ \\
\hline 4. & 14 & $1 \times 1$ \\
\hline 5. & 17.5 & $2 \times 2.3$ \\
\hline 6. & 18.5 & $2 \times 2$ \\
\hline 7. & 21 & $3 \times 3.2$ \\
\hline 8. & 21.5 & $1.5 \times 1$ \\
\hline 9. & 21.7 & $4 \times 4.5$ \\
\hline 10. & 23 & $3 \times 2$ \\
\hline 11. & 23.5 & $3 \times 3.5$ \\
\hline 12. & 23.5 & $4 \times 3.3$ \\
\hline 13. & 31 & $3 \times 4.5$ \\
\hline
\end{tabular}


Table 2. Weight of thymus compared with age and weight of foetus

\begin{tabular}{|c|c|c|c|}
\hline $\begin{array}{c}\text { SI. } \\
\text { No. }\end{array}$ & Estimated age (weeks) & $\begin{array}{c}\text { Weight of thymus } \\
\text { (gm) }\end{array}$ & $\begin{array}{c}\text { Weight of foetus } \\
\text { (gm) }\end{array}$ \\
\hline 1. & 12 & 0.040 & 100 \\
\hline 2. & 16 & 0.305 & 175 \\
\hline 3. & 16 & 0.650 & 115 \\
\hline 4. & 18 & 0.448 & 250 \\
\hline 5. & 20 & 1.360 & 520 \\
\hline 6. & 23 & 0.465 & 700 \\
\hline 7. & 24 & 1.350 & 400 \\
\hline 8. & 25 & 1.440 & 560 \\
\hline 9. & 26 & 3.900 & 2000 \\
\hline 10. & 27 & 4.630 & 1200 \\
\hline 11. & 28 & 1.800 & 1000 \\
\hline 12. & 30 & 5.390 & 1200 \\
\hline 13. & 36 & 3.900 & 2000 \\
\hline
\end{tabular}

Table 3. Average weight of thymus in foetus

\begin{tabular}{|c|c|c|}
\hline \multirow{2}{*}{ Age group (weeks) } & \multicolumn{2}{|c|}{ Weight of thymus (gm) } \\
\cline { 2 - 3 } & Range & Average \\
\hline $12-19$ & $0.040-0.650$ & 0.036 \\
\hline $20-29$ & $1.360-4.630$ & 1.760 \\
\hline$=30$ & $3.900-5.390$ & 4.645 \\
\hline
\end{tabular}

Table 4. Pearson correlation coefficient between gestational Age and thymus weight

\begin{tabular}{|l|c|c|}
\hline Group & $\mathbf{N}$ & $\begin{array}{c}\text { Correlation } \\
\text { coefficient }\end{array}$ \\
\hline Foetus & 13 & $0.787(* *)$ \\
\hline
\end{tabular}

** Correlation is significant at the 0.01 level (2-tailed).

\section{HISTOLOGY}

\section{Capsule :}

The thymus gland was completely surrounded by a connective tissue capsule with fibroblast and collagen (Figure 4). The capsule is broken by the entry and exit of neuro vascular bundles (Figure 5).
Graph 1. Compares the maximum breadth and height of foetal thymus gland in different studies

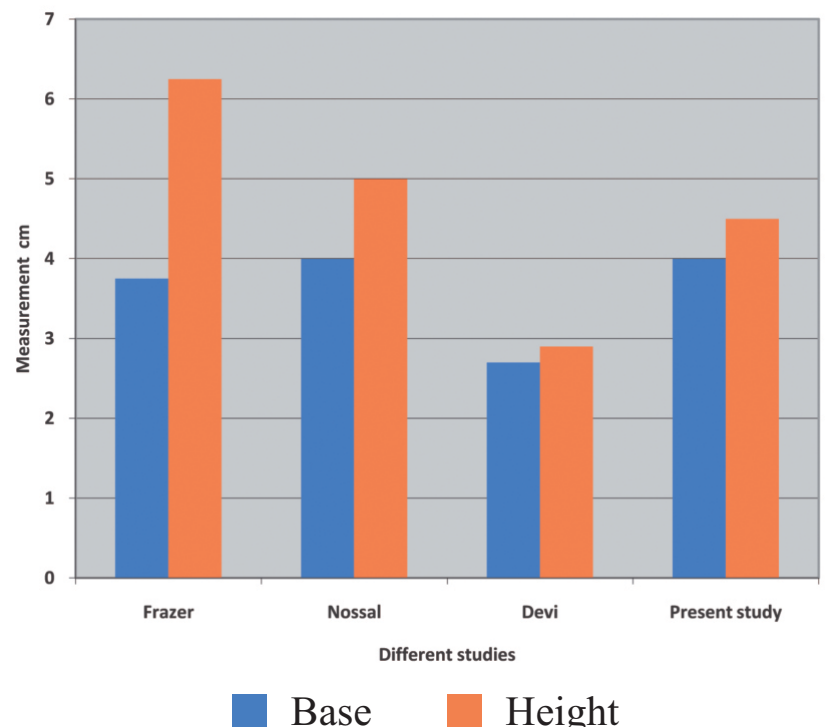

\section{Septae :}

The connective tissue of the capsule extended into the gland as septae and this formed the lobule (Figure 6). The blood vessels invaded the parenchyma of the gland through these septae. Few adipocytes were also seen in the septae.

\section{Lobule :}

Each lobule had an outer cortex and an inner medulla (Figure 7) Cortex was darkly stained with more lymphocytic infiltration. The medulla was sparsely filled with lymphocytic cells. The medulla had hyalinised bodies, the Hassall's corpuscles. They were oval to round shaped and at times irregular (Fig: 8). Two types of Hassall's corpuscles were observed in the thymus (a) small concentric type and (b) large cystic type (Figure 9). The concentric types of Hassall's corpuscles were arranged in whorls like onion peel and represent the degenerated epitheliocytes taking eosinophilic stain. The cystic types of Hassall's corpuscles had a central core of degenerated, hyalinisedeosinophilic material surrounded by cystic spaces around. These variable types were seen within the same lobule. 
The cortico-medullary junction was clearly seen in all pre-viable foetal thymus (Figure 10). The cells seen in this zone were the macrophages. They had agranular cytoplasm with reniform nuclei, which were darkly stained and occupy greater part of the cell. In all sections the lymphocytes were the main cells seen in the thymus gland. These were seen in the cortex in large numbers and in the medulla in lesser numbers. Apart from lymphocytes, the epithelial reticular cells were also seen. They were spindle shaped and are present in the blood vessels and in Hassall's corpuscles. The cytoplasmic extension of epithelial reticular cell, which form a network was not clearly seen. The invasion of cortex by adipose cells (Figure 11) was also observed in aging foetal specimens.

\section{Blood Vessels:}

Blood vessels and their branches were seen in the septae, in the cortico-medullary junction and in the parenchyma. Spindle shaped epithelial reticular cells (Figure 12) were seen on the vessel walls and perivascular connective tissue. Veins were also seen in the interlobular septa.

Figure 1.Thymus extending into the anterior mediastinum at its lower limit

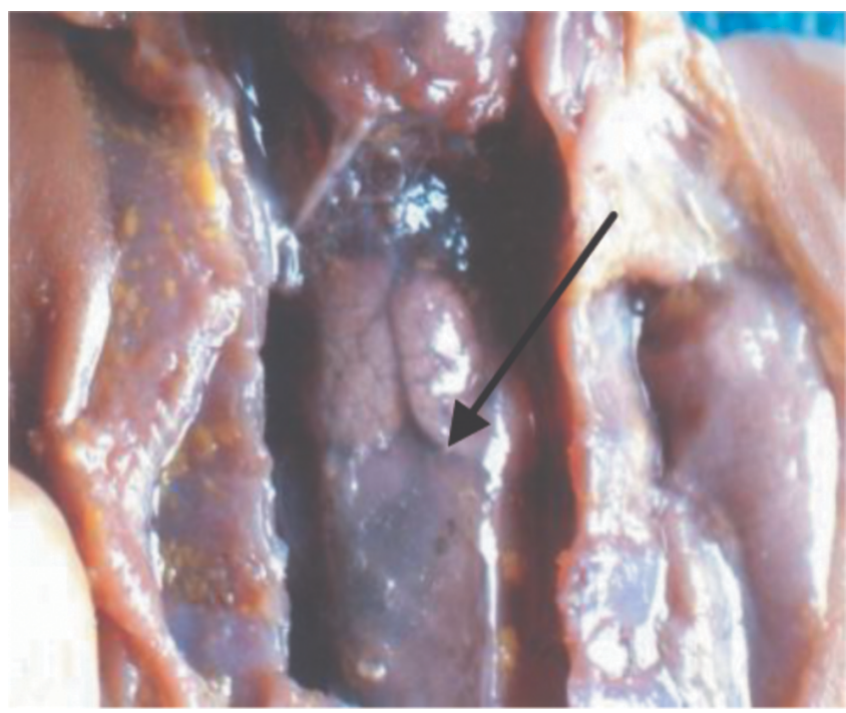

\section{Figure 2. Thymus with multiple lobulations (shown with arrows)}

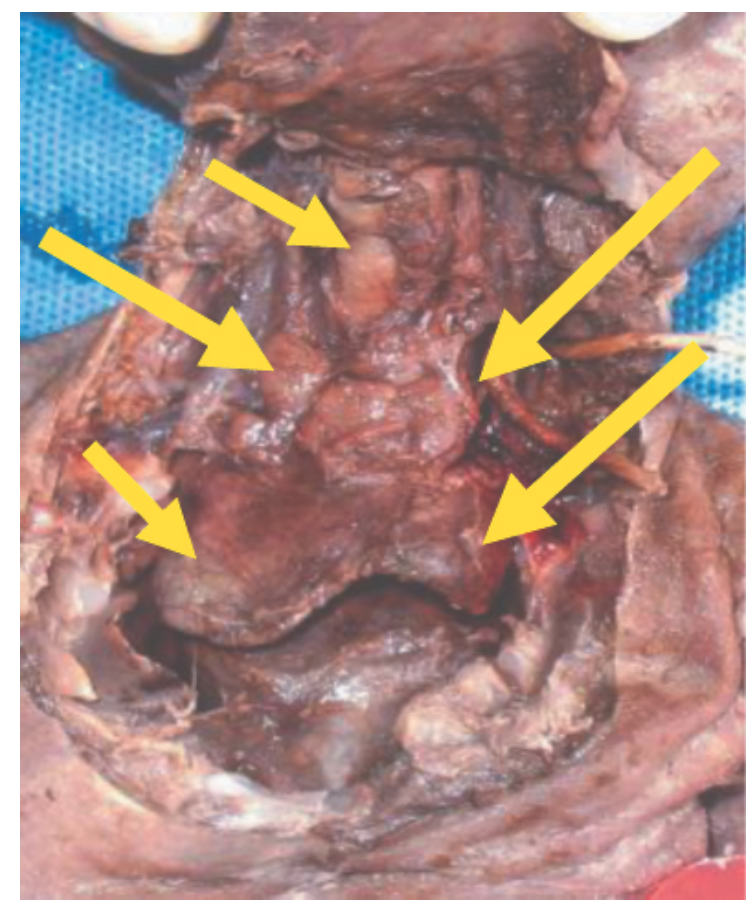

Figure 3. Pyramidal shaped gland

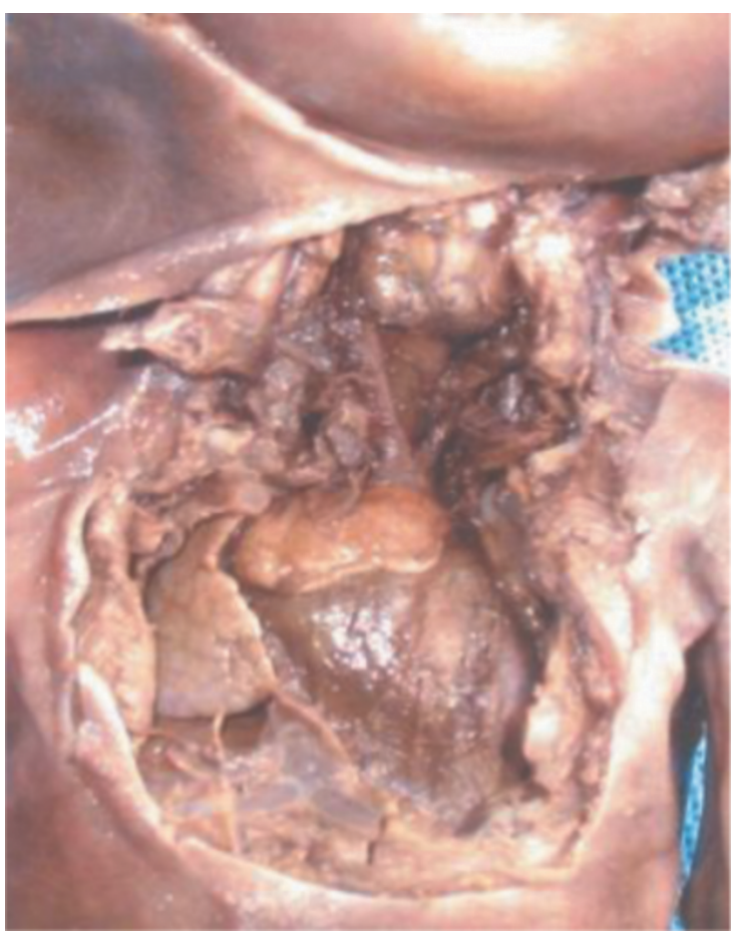


Figure 4.Capsule and connective tissue elements (shown as arrow) (Trichrome)

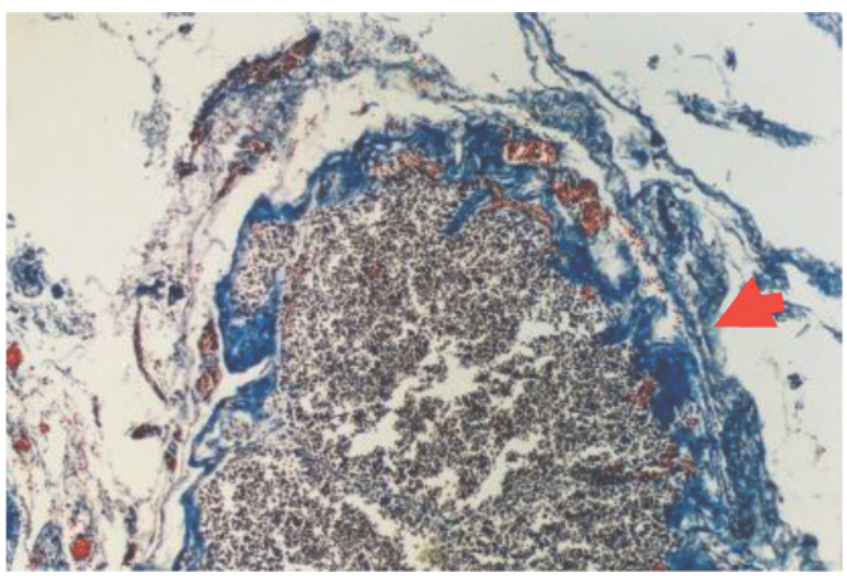

Figure 5.Entry of blood vessels (arrow mark) in between the lobules (TPA)

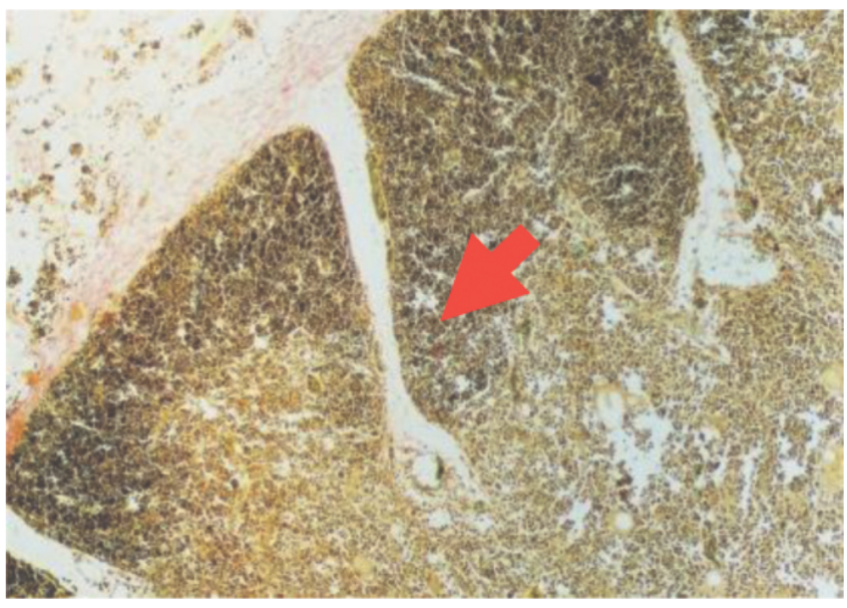

Figure 6. The septae (shown as arrows) are responsible for the formation of the lobules (H\&E)

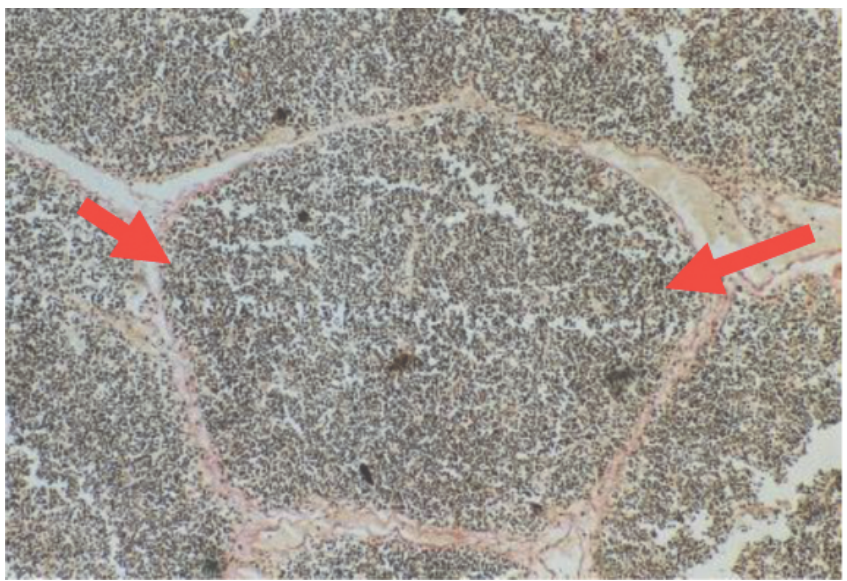

Figure 7.Cortex and medulla clearly shown

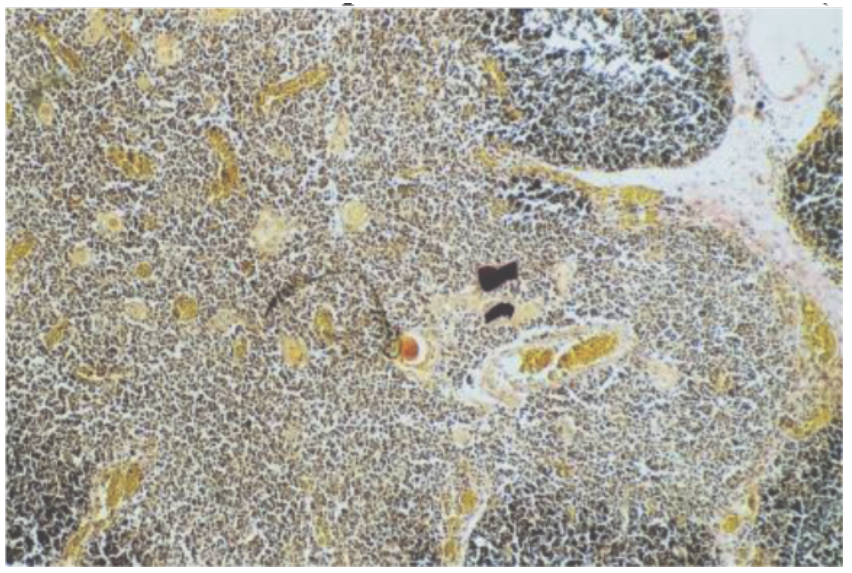

Figure 8. Hassall's corpuscles of different shapes and sizes are present in the medulla $(\mathrm{H} \& \mathrm{E})$

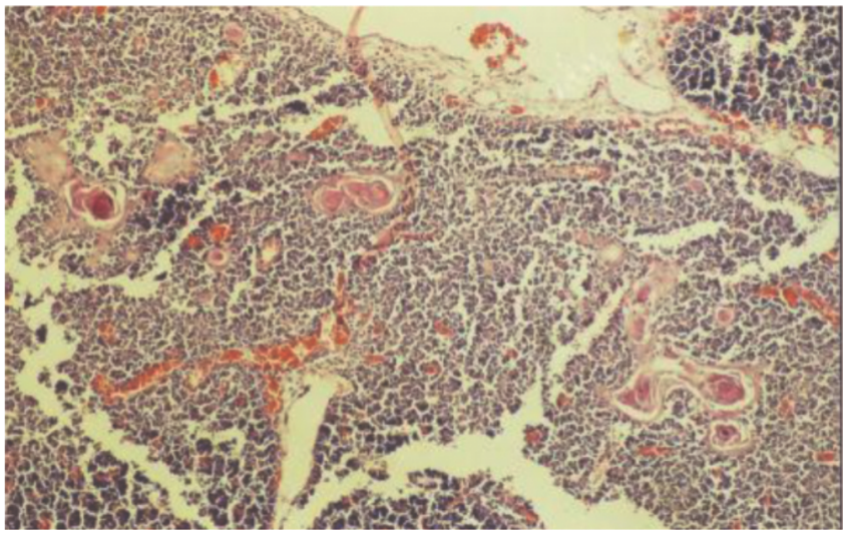

Figure 9. Hassall's Corpuscles are of two types (TPA): a.Concentric b. Cystic

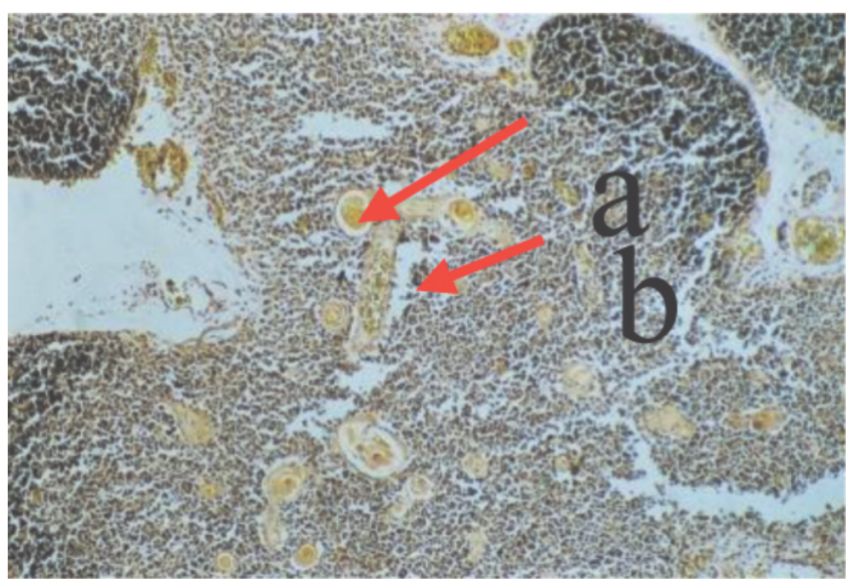


Figure10. Cortico-medullary junction with blood vessels is clearly seen (Trichrome)

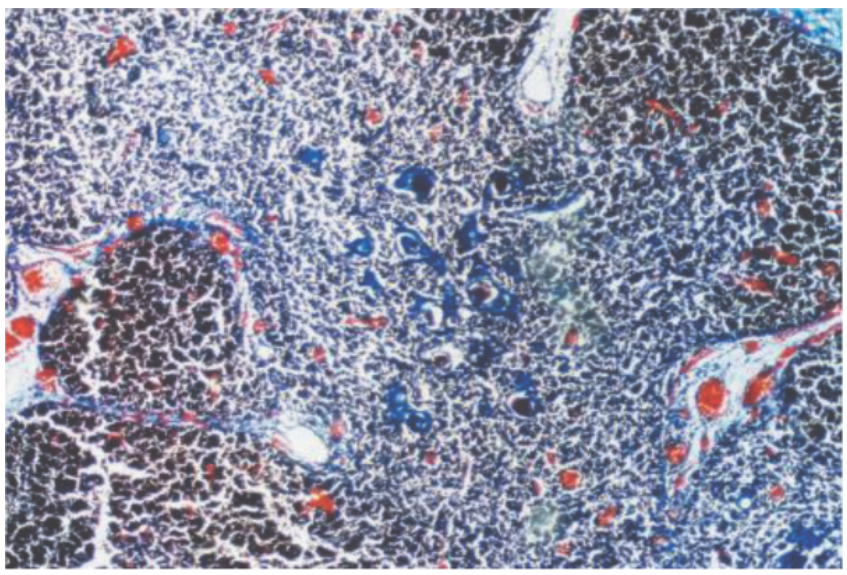

Figure 11. Adipose cells (marked A) are seen (H\&E)

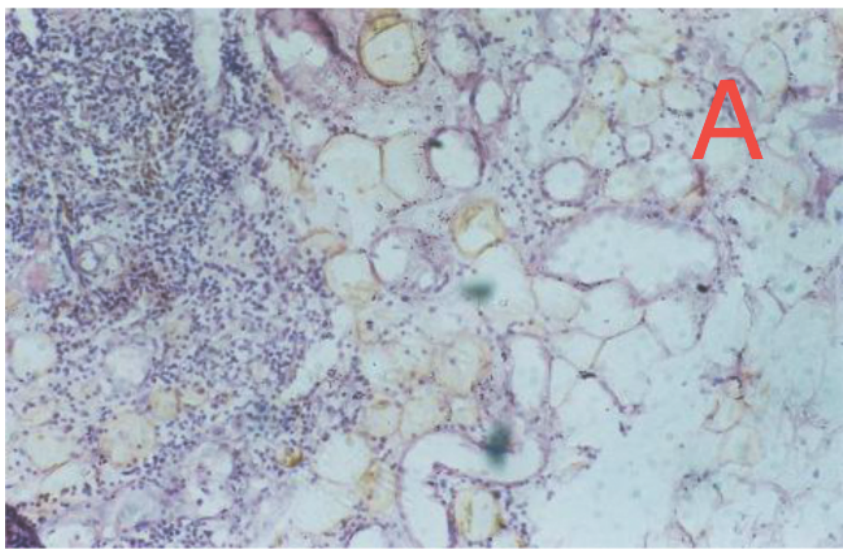

Figure 12. Epithelial reticular cells (arrow mark) on the vessel wall (H\&E, High Power)

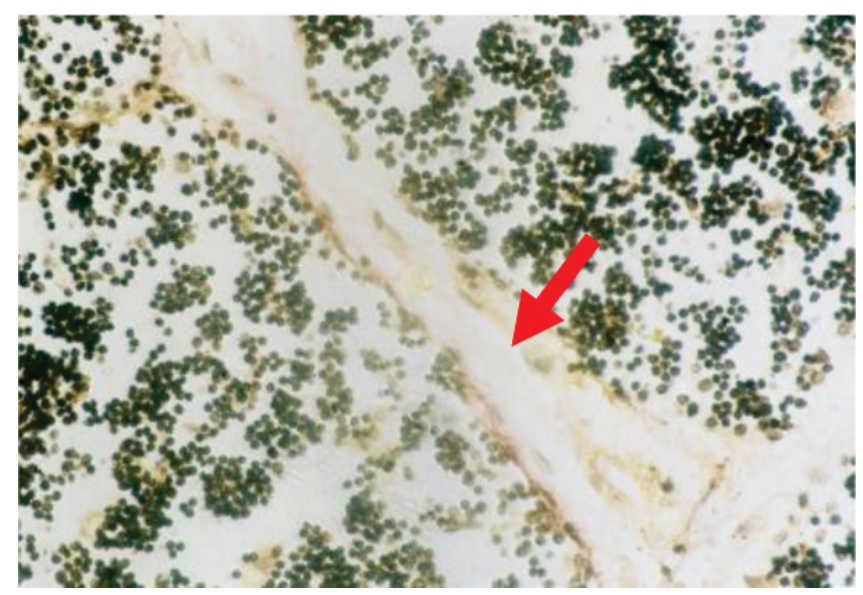

\section{DISCUSSION :}

\section{MORPHOLOGY}

The thymus is a bilobed organ located in the superior mediastinum of thorax, above the heart and behind the sternum. ${ }^{11}$ The characteristics like shape, position, lateral contour, degree of fatty infiltration, amount of residual thymic tissue have been the areas of research in sectional CT images. ${ }^{12}$ Thymic index, based on the size of the gland can be correlated as a volume estimate in ultrasonography studies. ${ }^{10}$ In the present study the extent, number of lobes, shape, size, weight were inspected by dissecting the foetus. This explains the details in a more explicit manner and enables better understanding of the gland in situ. Measuring the thymus is far more complicated than measuring other structures because of its age-related changes. ${ }^{13,14}$

\section{Extent of the thymus gland}

The resultant migration of the thymus from the neck, accompanying the descent of the pericardium and the heart ${ }^{15}$ can contribute to the determination of its extent. This can be evidenced by the fact that majority of the specimens tapered from the neck above cricoid level and embraced the pericardium at its lower limit. ${ }^{16}$ One gland extended from cricoid cartilage level. Two thymus glands extended from thyroid gland. ${ }^{17,18,19}$ In some studies the gland was found to lie at the level of angle of mandible ${ }^{20}$ and in others it extended up to hyoid bone. $^{21}$ However such extensions were not identified in the present study.

\section{Number of lobes}

Thymus gland is developmentally from two sides of the pharyngeal apparatus and hence is bilobed. The asymmetry of the lobe can be attributed to the 
development of the thymus from the $3 \mathrm{rd}$ and 4 th pharyngeal pouches and its subsequent descent. ${ }^{16}$ There was preponderance of asymmetrically bilobed glands ${ }^{18,19,22,23}$ connected by fibrous connective tissue across the midline ${ }^{15,16}$ and they showed smooth surface. Multilobularity is not normal at any age and is seen in patients with abnormality. ${ }^{12}$ Multiple surface lobulations ${ }^{18}$ were seen in 2 foetal specimens in the present study.

\section{Shape of the thymus gland}

This bilobed organ can be visualized as pyramidal, quadrangular, triangular or arrowhead shaped in cross sectional computed tomography images. ${ }^{4,7,9}$ In the present study, direct surface visualization has enabled us to identify a large share of both oval and pyramidal shaped glands. ${ }^{15,18}$ The variability in the shape of the thymus is enormous. ${ }^{16}$

\section{Measurement of the thymus gland}

The craniocaudal extent, maximum transverse dimension and thickness were measured using the soft tissue density of thymus gland in sectional CT image studies. Logarithm of these measurements were plotted against age to identify if it is a useful predictor of thymic abnormality. ${ }^{12}$ Transverse diameter was analyzed as a sensitive indicator of thymic abnormality, yet accurate recognition of abnormality was not possible. ${ }^{12}$ According to a study in Guinea Bissau in urban West African community, where death was due to infectious disease, the reduced size of thymus was an important predictor of immune competence and thus infant mortality. ${ }^{24}$ In the present study the gland measurement ranged from $0.6 \times 0.5 \mathrm{~cm}$ to $4 \mathrm{x}$ $4.5 \mathrm{~cm}$ (base $\mathrm{x}$ height) (Table1). The maximum breadth and height of foetal thymus gland in different studies is compared in (Graph 1)

\section{Weight}

The growth curve of thymus gland suggests that it weighs around $15 \mathrm{gms}$ at birth, steadily increases up to puberty when it attains a maximum weight of 35 gms and reduces thereafter with advancing age. $^{16,25 \cdot 26,27,28,29}$ Clinical study indicates that the gland involutes in fatigue, famine, fever and formula fed infants. ${ }^{10}$ This gland is heavier in males with large thymic indices ${ }^{24}$ than in females. ${ }^{23}$ In the present study it was observed that in the foetal period of 12 to 19 gestational weeks the average weight of the thymus gland was $0.036 \mathrm{gm}$. In 20 to 29 gestational weeks the average weight of the thymus gland was found to be $1.760 \mathrm{gm}$. Above 30 weeks the average weight was $4.645 \mathrm{gm}$ (Table 3). The gland was found to progressively increase in weight after the period of viability. Pearson correlation coefficient between gestational age and thymus weight suggests that with increase in the gestational age there is increase in thymus weight in the foetus. This shows positive Pearson correlation. The correlation is 0.787 and is significant at $1 \%$ level (0.01). (Table 4).

\section{Histology of the thymus gland:}

Among the various lymphoid tissues, the thymus is histologically most consistent across species. ${ }^{30}$ It is unique among the lymphoid organs in being an epithelial organ.

\section{Capsule and Septa of the thymus gland}

The thymus gland is enclosed by connective tissue capsule, the delicate septae which arise from the capsule subdivides the thymus gland into numerous incomplete interconnecting lobules ${ }^{23,31,32,33}$ of variable size and orientation. ${ }^{34}$ The capsule is composed of an outer and inner layer of collagen ${ }^{16}$ and reticular fibres, ${ }^{34}$ between which are occasional clusters of lymphocytes..$^{34,35}$ Various studies 
describe the presence of blood vessels, ${ }^{16,36}$ accumulation of adipocytes ${ }^{31}$ within the septae. Some enumerate epithelial cells, ${ }^{36}$ capillaries, fibrocytes $^{37}$ in the trabeculae. In the present study the thymus gland was enclosed in the connective tissue capsule as shown by Masson's trichrome stain but the outer and inner layer of capsule was not well demarcated. Septae extended from the capsule into the parenchyma of the gland (Figure 1) and had the presence of blood vessels and adipocytes. The presence of capsule was observed in the thymus sections from foetus of 12 weeks gestational age. Extensive septae and distinct trabecular framework was noted in sections from older specimens. ${ }^{38}$

\section{Lobulation, Cortex and Medulla of the thymus gland}

In the present study, the thymus is divided morphologically into two distinct sub compartments the cortex and medulla separated by a vascular corticomedullary zone. ${ }^{15,23,30,35,39,40}$ There is progressive loss of demarcation of cortex and medulla with advancement in age. ${ }^{41,42,43}$ The cortex is darkly stained with densely packed lymphocytes ${ }^{23,31,35,37,44}$ and medulla is continuous between adjacent lobules, ${ }^{15,16,35}$ its paler with a sparse population of lymphocytes. ${ }^{32}$ The other cellular components seen are stromal macrophages.

\section{Blood vessel}

In the present study blood vessels are seen in the septa, parenchyma, corticomedullary junction. Perivascular connective tissue is also seen. ${ }^{15,16}$ The haemothymic barrier is formed by capillary endothelium, basement membrane, perivascular space, basement membrane and epithelial reticular cells. $^{6,31}$

\section{Lymphocyte}

In the present study lymphocytes were identified as the main cells in the thymus gland. The cortex was basophilic when compared to the medulla which was eosinophilic. ${ }^{36}$ In one of the studies it has been found that the stem cells ${ }^{28}$ are present in the cortex and subcapsular cortex ${ }^{39}$ region. They divide by mitosis to form small lymphocytes..$^{35,36,45}$ The medium to large blast like lymphoid cells were present in medulla. ${ }^{45}$ They were paler staining and had more cytoplasm. ${ }^{35}$ The size of lymphocytes was found to be variable in the cortex and medulla. The presence of early, intermediate and mature lymphocytes in wide spaces between epithelial reticular cells has also been identified. ${ }^{31}$

\section{Reticular Epithelial Cells:}

These reticular cells are distinguished from the reticular cells of mesodermal origin in the spleen and lymph nodes. Their epithelial origin is proved by presence of keratin in Hassall's corpuscle and by the presence of tonofilaments and desmosomes. Hence these cells are also called "Epitheliocytes"46 In the present study spindle shaped epithelial reticular cells were identified. ${ }^{16,38}$ Some authors report stellate shaped cells. ${ }^{15,36,47}$ In the present study epithelial cells were seen in and around the blood vessel in the septa. ${ }^{15,16,35,37}$ Also, epithelial cells were identified in the Hassall's corpuscles ${ }^{15,32,35,37}$ Some authors identified epithelial cells in the cortex, to be fine and delicate. In medulla these cells were robust; While others identified more number of epithelial cells in the medulla. Other studies revealed the presence of these cells in the subcapsular region, cortex, medulla ${ }^{15,16,37,45}$ corticomedullary junction. The epithelial reticular cells formed a cellular network, which provided support for other cells of the thymus ${ }^{32,35}$ 


\section{Hassall's corpuscles}

Hassall's corpuscles attribute their origin to thymic epithelial cells ${ }^{48}$ and have a secretory function ${ }^{49}$ The Hassall's corpuscles are seen in fetal thymus only after 15 weeks, when the cortex and medulla begin to differentiate, but its size is very small ${ }^{50}$ and is present in the medulla ${ }^{15,23,31,32,36,38}$ The Hassall's corpuscle have been found to be comet, club, elongated or tricyclic, ${ }^{51}$ spherical, ${ }^{23}$ nest like bodies, irregular $^{16,}$ oval $^{16,33}$, or rounded ${ }^{32}$ in shape. According to the present work Hassall's corpuscles were mostly oval, rounded and irregular. Hassall's corpuscle have been found to exhibit polymorphism. ${ }^{51}$ Hassall's corpuscle ranged from an enlarged single epithelial cell to a large cystic structure. $^{52}$ In the present study, the Hassall's corpuscle had concentrically arranged flattened epithelial cells around a central eosinophilichyalinising mass with keratinization 15,16,23,31,32,33 The Hassall's corpuscle before the period of viability (28 weeks) and after 28 weeks were different in size, structure and appearance. Its size increased and was solid in nature before the period of viability but in post viable period its size diminished and was of cystic type. In the present study the specimens included were both in pre-and post-viable period of gestation and this was evidenced by the presence of hyalinised Hassall's of both types (a) small concentric type ${ }^{15,16,23,31,32,33}$ and (b) large cystic type. ${ }^{16,33}$

One of the studies has described four stages of Hassall's corpuscle, namely juvenile, premature, mature and advance stage. In juvenile stage one or two reticuloendothelial cells were present, in premature stage small groups of reticuloendothelial cells in concentric disposition with keratinization were seen, in mature stage reticuloendothelial cells were flattened, concentrically placed around keratin mixed with degenerated lymphocytes and macrophages with or without empty spaces, in advance stage Hassall's corpuscle fused with nearby Hassall's corpuscle and were polymorphic..$^{53}$ In the present study majority of the Hassall's corpuscle seen were of the premature, mature and advanced stage.

\section{Adipose cells}

Adipocytes deposited in the perivascular space s1,42 $^{40}$ progressively increase in the interlobular tissue ${ }^{16}$ accumulate in the septa ${ }^{31}$ infiltrate the cortex and gradually replace the lymphocytes ${ }^{15}$ in the parenchyma of the gland $d^{33,54}$ The adipocyte deposition begins at birth, their numbers slowly rises until puberty later spreading onto the medulla. ${ }^{36}$ In the present study of foetal thymus, adipocytes were present in the septa, they were also seen to invade the cortex and areas of adipose tissue separated islands of lymphoid tissue.

\section{CONCLUSION :}

Thymus has a unique morphology and histology in different age groups. As the CRL increases there is increase in the size of the gland. The weight of the thymus gland was made as a direct estimate in this study. It was found to progressively increase after period of viability. This was justified by the positive Pearson correlation and its significance was established. The capsule was observed at 12 weeks. The extensive septal formation and deposition of adipocytes within the parenchyma, occurred with advancement in age of the foetal thymus. The cortex is densely populated with lymphocytes when compared with medulla. As age advances the demarcation between the two is progressively lost. The concentric type of Hassall's corpuscles changed to cystic type in post viable period. Limitation has been that a small number of foetus has been used for this study. Yet analyzing the thymus gland at different gestational age will essentially give important insights and will also help us to improve the application of these results. The involution of thymus gland, reflected in its 
morphology and histology can serve as a baseline to identify many diseases and can be used as a complement in screening the developing foetus. This being a non-invasive method, can also be safely and widely used to foretell the well-being of the unborn foetus.

\section{References:}

1. Miller J. FAP Immunological function of the thymus. Lancet. 1961;2:748-9.

2. JingangGui, Lisa Maria Mustachio, Dong-Ming Su, Ruth W. Craig. Thymus size and age related thymic involution: Early programming, sexual dimorphism, progenitors and stroma. Ain and Disease. June 2012; 3(3): 280-290.

3. Shanley DP, Aw D, Manley NR and Palmer DB. An evolutionary perspective on the mechanisms of immunosenescence. Trends Immunol. 2009; 30:374-381.

4. Araki T, Sholl LM, Gerbaudo VH, Hatabu H, Nishino $M$. Imaging characteristics of pathologically proven thymic hyperplasia: identifying features that can differentiate true from lymphoid hyperplasia. AJR American Journal of Roentgenology. 2014; 202:471-478. [PubMed: 24555583]

5. Gewolb IH, Lebowitz RL, Taeusch HW Jr. Thymus size and its relationship to the respiratory distress syndrome. J Pediatr.1979 Jul;95(1):108-11.

6. Y. Yinon, Y. Zalel, B. Weisz, S. Mazaki-tovi, E. Sivan, E. Schiff, R. Achiron.Fetal thymus size as a predictor of chorioamnionitis in women with preterm premature rupture of membranes. Ultrasound obstet gynecol. 2007; 29: 639-643.

7. Baron R, Lee J, Sagel S, Peterson R. Computed tomography of the normal thymus. Radiology.1982; 142:121-125. [PubMed: 7053521]

8. Baron R, Lee J, Sagel S, Levitt R. Computed tomography of the abnormal thymus. Radiology. 1982;142:127-134. [PubMed: 7053522]
9. Ackman JB, Kovacina B, Carter BW, et al. Sex difference in normal thymic appearance in adults 20-30 years of age. Radiology. 2013; 268:245-253. [PubMed: 23440318]

10. Hasselbalch H, Jeppesen DL, Ersbøll AK, Engelmann MD, Nielsen MB.Thymus size evaluated by sonography. A longitudinal study on infants during the first year of life.ActaRadiol. 1997 Mar;38(2):222-7.

11. Gordon J and Manley NR. Mechanisms of thymus organogenesis and morphogenesis. Development. 2011;138:3865-3878.

12. Francis I, Glazer G, Bookstein F, Gross B. The thymus: re-examination of age-related changes in size and shape. American journal of roentgenology. 1985; 145:249-254. [PubMed:3875220]

13. Standering S, Ellis H, Healy J.C, Johnson D, Williams A. Gray's anatomy - The Anatomical Basis of Clinical Practice. 39th(Ed.) 2005 Churchill Livingstone, Elsevier New York. 980 984.

14. Kendall M.D, Johnson H, Singh J. The weight of the human thymus gland at necropsy. Journal Anatomy. 1980; 131:485-99.

15. Gray H, Williams P.L, R.Warwick, Dyson M, Bannister L.H. Gray's Anatomy37th edition. London, Churchill Livingstone; 1989: 833-838.

16. Kathiresan S. The Human Foetal Thymus.1969; 121,239-240.

17. Lee Mc.Gregor A. Synopsis of Surgical Anatomy 12th (Indian) edition. K.M Varghese Company, Mumbai.1999;205-206.

18.Frazer J.E. Buchanan's Mannual of Anatomy 6th ed.London: Balliere, Tindall\& Cox,1937; 1020.

19. Hollinshead WH. Anatomy for Surgeons (2nded).). Hoeber Medical Division, Harper \&Row 1968; 1:590.

20. Harman N.B. Socio thymus cervicalis and thymus accessories. J.Anat\& Phys. 1901;36:47 
21. Bien, Gertrud. AnatAnz, 1906;29:325.

22. Keynes G. Brit.Med.J.1954;2:659.

23. J.D.Boyd, W.J.Hamilton. Textbook of Human Anatomy 1956; 671.

24. Aaby P, Marx C, Trautner S, Rudaa D, Hasselbalch $\mathrm{H}$, Jensen $\mathrm{H}$, Lisse I. Thymus size at birth is associated with infant mortality: a community study from Guinea-Bissau. ActaPaediatr. 2002;91(6):698-703.

25. Boyd E. The weight of the thymus gland in health and disease.Am J Dis Child. 1932; 43:1162-1214.

26. Steinmann, G. Changes in the human thymus during aging. The Human Thymus. Springer, New York City, New York.1986; p 43-88.

27. Kumar V, Abbas AK, FaustoN,.Robbins and Cotran. Pathologic Basis of Disease. 2004;706-8.

28. Nishino M, Ashiku SK, Kocher ON, et al. The Thymus: A Comprehensive Review. Radiographics.2006; 26:335-348. [PubMed: 16549602]

29. Nasseri F, Eftekhari F. Clinical and Radiologic Review of the Normal and Abnormal Thymus: Pearls and Pitfalls. Radiographics.2010; 30:413-428. [PubMed: 20228326]

30. Haley, P. J. Species differences in the structure and function of the immune system. Toxicology.2003; 188:49-71.

31. David H.Cormack. Ham's Histology, 9th edi.1987; 242-246.

32. InderBir Singh. Text book on Human Histology.2007; 193-194.

33. Victor P. Eroschenko. Di Fiore's. Atlas of Histology, 10th edi.2003;176-179.

34. Gail Pearse et al. Normal Structure, Function and Histology of the Thymus. Toxicologic Pathology.2006; 34:504-514. (ISSN: 0192-6233 print/1533-1601 online)
35. Astra Zeneca, Alderly Park. Toxicologic Pathology.2006; Vol.34, no.5:504-514.

36. Barbara Young, James.S.Cowe. Wheater's Functional Histology,5th edi.2007;215-7.

37. M.G.Mohammad. Anatomy and cytology of the thymus in Juvenile Australian Lungfish, NeoceratodusForsteri.J of Development, Evolution, Function. Dec 2007; Vol.211, Issue6:784-797.

38. R.K.Ajita. An insight into the structure of the thymus in human foetus- a histological approach. J.Anat.Soc.India.2006; 55(1)45-49.

39. Blackburn CC and Manley NR: Developing a new paradigm for thymus organogenesis. Nat Rev Immunol.2004; 4:278-289.

40. Skogberg G, Lundberg V, Berglund M, Gudmundsdottir J, Telemo E, Lindgren $\mathrm{S}$ and Ekwall O: Human thymic epithelial primary cells produce exosomes carrying tissue-restricted antigens. Immunol Cell Biol. 93: 2015;727-734.

41. Taub DD and Longo DL. Insights into thymic aging and regeneration. Immunol Rev.2005; 205: 72-93.

42. Aw D, Taylor-Brown F, Cooper K and Palmer DB. Phenotypical and morphological changes in the thymic microenvironment from ageing mice. Biogerontology. 2009;10:311-322.

43. Gui J, Zhu X, Dohkan J, Cheng L, Barnes PF and Su DM. The aged thymus shows normal recruitment of lymphohematopoietic progenitors but has defects in thymic epithelial cells. IntImmunol, 2007;19:1201-1211.

44. Kurt.E.Johnson. National Medical Series. Histology and cell biology,2nd edi.1990;144-148.

45. Nicla Romano, Monica Fanelli. Comparitive Anatomy and Zoology, TusciaUniversity, Viterbo, Italy.1998.

46. Kendall M.D. (1981) The cells of the thymus. In: The Thymus Gland (ed. M. D. Kendall), p. 63. Academic Press, London. 
47. Ramayya et al. (2006) Studied on distribution pattern of argyrophilefibers in the thymus of prenatal buffalo. XXI IAVA Convention Technical Bulletin.pp. 51

48. B, Bodey B Jr, Siegel SE, Kaiser HE. Novel insights into the function of the thymic Hassall's bodies. 2000; 14(3): 407-418.

49. Nishio H, Matsui K, Tsuji H, Tamura A, Suzuki K. Immunolocalization of mitogen activated Protein kinase signalling pathway in hassaals corpuscle. ActaHistochem. 2001; 103(1): 89-98.

50. P. Devi Raja Rajeswari, K. Aruna, Raja Sankar S. Comparative Morphological And Anatomical Study On Thymus Gland Of Human And Primate. Int JAnat Res. 2014; 2(3): 507-510.
51. AdilAsghar, Yunus M Syed, Faruqi A Nafis.Polymorphism of Hassall's corpuscles in thymus of human foetuses.Int J Appl Basic Med Res. 2012 Jan-Jun; 2(1): 7-10.

52. Seigler R. The morphology of thymuses and their relation to leukaemia.In: GoodRA, Gabrielsen AE (eds) The thymus in immunobiology. Harper and Row, New York, 1964; 623.

53. Blau J.C. Hassall's Corpuscles - Site of thymocyte death. Br.J.Exp.Path. 1973; 53: 634.

54. Haynes B.F, Markert M.L, Sempowski G.D, Patel D.D, Hale L.P. The role of thymus in immune reconstitution in aging, bone marrow transplantation, and HIV-I infection. Annual Review of Immunology. 2000; 18: 529-60.

Received on 10/11/2017 Revised on 24/11/2017 Accepted on 26/11/2017 